CuPAUAM. 15-1988

\title{
LAS ACANALADURAS EN LAS HOJAS DE FALCATAS IBERICAS
}

\author{
FERNANDO QUESADA SANZ \\ Dpto. Prehistoria y Arqueología. \\ Universidad Autónoma de Madrid
}

\begin{abstract}
Resumen
Uno de los rasgos distintivos de la falcata ibérica es la presencia de acanaladuras sobre la superficie la hoja, que sin embargo no han sido hasta ahora estudiadas con detalle. Nuestro próposito en este artículo es proponer un criterio de descripción que considere las distintas variantes existentes. A partir de este sistema analizamos la distribución geográfica y temporal de dichas variantes, con la intención de determinar si es posible utilizarlas como criterio de datación o procedencia. Igualmente estudiamos la relación de estas acanaladuras con sus prototipos itálicos, describiendo las mejoras realizadas, y por último analizamos su funcionalidad.
\end{abstract}

\section{Summary}

The presence of grooves cut on the surface of the blade is one of the distinctive features in the Iberian falcata (a type of short, one-edged, slashing sword), a trait which however has not been studied in detail so far. Our pupose in this paper is to suggest a taxonomy which takes into account the different variants. Using this typology as a starting point, we have analised the geographical and chronological distribution of those variants, in order to determine whether falcatas can be dated or located using them as a criterion. We have studied the relationship of these grooves with those found in Italic prototypes, describing Iberiam improvements. Lastly, we analyse the function of grooves on blades.

Las acanaladuras en la hoja son un elemento presente en la inmensa mayoría de las falcatas ibéricas, aunque a menudo se hayan perdido sus trazas debido al intenso grado de corrosión de las hojas conservadas. Formalmente son una característica importante, y en las falcatas representadas en escultura los diferentes artistas se preocuparon de tallarlas con fidelidad, como ocurre en los conjuntos - realizados en épocas muy distintas - de Porcuna, Osuna o Elche. En este artículo pretendemos estudiar los distintos tipos de acanaladura, determinar 
si las variantes se deben a una evolución en el tiempo o a la existencia de talleres regionales, y tratar de explicar su funcionalidad.

No se ha realizado, que sepamos, ningún estudio detenido de este elemento aunque existan alusiones más o menos detalladas en algunos trabajos. Coincidimos con Cuadrado (1987, 84 ) en el uso del término acanaladuras. que en nuestra opinión recoge mejor que ningún otro las caracteristicas de ranura ancha, separada de otras más o menos paralelas bien por aristas bien por planos. Sin embargo, se han utilizado también los términos razas y muescas (LATO. RRE, 1979, 161), canalillos (BLÁZQUEZ Y GARCíA GELABERT, 1989, 108), surcos (CABRÉ, 1934, 8), estrias (CUADRADO, e. p., 5 y CABRÉ, 1934a, 8) y también nervaduras (NIETO Y ESCALERA, 1970, 30).

\section{TIPOS}

Como hemos dicho, las acanaladuras se realizaron en todas o casi todas las falcatas ibéricas. Sólo en los casos en que la hoja se ha conservado en buen estado, conservando una característica capa superficial de color negro-azulado brillante, es posible observar la gran calidad del trabajo efectuado por los herreros ibéricos. En líneas generales, se trata de una serie de acanaladuras sensiblemente paralelas unas a otras y al dorso de la hoja, en número variable. Arrancan desde la base de la empuñadura y no llegan nunca hasta el extremo de la hoja, extinguiéndose a unos $10-15 \mathrm{~cm}$. de la punta. A menudo son bastante profundas, hasta casi $2 \mathrm{~mm}$. en cada lado de la hoja. Fuera de esta generalidad las variantes son muchas, casi tantas como falcatas se conservan, y pueden ser descritas y analizadas según una combinación de los siguientes factores:

A. Número de acanaladuras: Varía entre piezas sencillas, en las que se practicó una sola acanaladura ancha, y otras muy complejas en las que se juega con combinaciones de acanaladuras anchas y romas y estrías afiladas y estrechas, hasta un número de siete o más (Fig. 1).

B. Forma de las acanaladuras: Pueden ser anchas y con el fondo plano, o curvo en forma de «U». También pueden ser estrechas y con fondo en «U» o incluso estrías delgadas y con el fondo en $₫ \mathrm{~V} »$. Aunque podría parecer tentador realizar una tabla descriptiva con estos caracteres, en realidad dicha Tipografía no sería operativa porque sólo en algunas piezas excepcionalmente bien conservadas es posible precisar el tipo de acanaladura. La descripción utilizada por nosotros es la siguiente (Fig. 2-E).

\section{FORMA}
A Ancha y fondo plano
B Ancha y fondo curvo en «U»
C Estrecha y fondo en " $\mathrm{U}$ "
D Estrecha y fondo en $" \mathrm{~V}$ »

(Una serie de acanaladuras en una falcata podría ser descrita, de izqda. a dcha., del siguiente modo: D-A-D-A-A (Fig. 2-A) o D-B-C-C-A-C-C-B (Fig. 2-B) pero debe tenerse en cuenta que según el sitio en que hagamos la sección la forma de las mismas puede variar. 

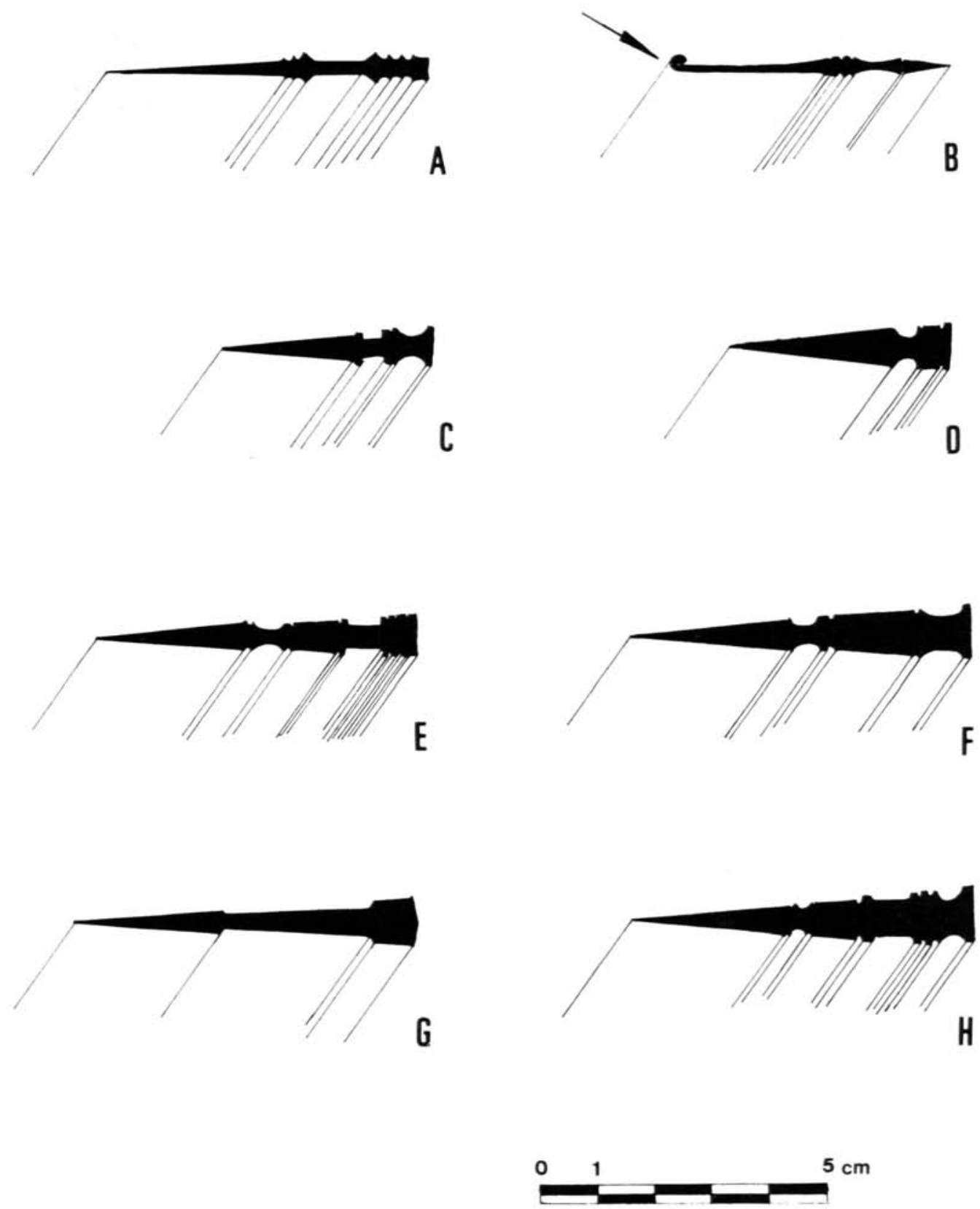

FIG. 1. - Secciones de hojas de falcata, mostrando distintos tipos de acanaladuras. A-B zona próxima a la punta; C-D zona estrangulada de la hoja; E-H zona próxima a la empuñadura. A-Mus. Cerralbo, N. Inv. 931; B-Mus. Cerralbo, 1308. Filo mellado a golpes; C-British Museum, WG1954; D-Mus. Cerralbo, 931; E-Mus. Cerralbo, 1308; F-British Museum, 1890. 8-10.1; G-Mus. de Córdoba, 1059; HBritish Museum, WG1955. 
C. Disposición de las acanaladuras en la parte de la hoja más próxima a la empuñadura: Es el único factor que ha sido tenido en cuenta por autores anteriores, que han distinguido entre las piezas cuyas acanaladuras son paralelas hasta el final de la hoja y aquellas en las que éstas divergen, abriéndose, justo al final, donde la hoja se ensancha. En esta dualidad se ha querido ver un factor cronológico como más adelante analizaremos. En nuestra Base de Datos, este factor se describe del siguiente modo (Fig. 2-A y 2-B).

\section{DISPOSICION}

$0 \quad$ Hay acanaladuras, pero no se puede determinar el tipo.

1 Divergen al llegar a la empunadura.

2 Se mantienen paralelas al llegar a la empuñadura.

3 No hay acanaladuras.

$4 \quad$ No es posible determinar si existen o no acanaladuras.

Dentro de la variante 1 es posible diferenciar una subvariante consistente en que las acanaladuras llegan paralelas hasta el fin de la hoja, pero se imita el modelo de estrías divergentes realizando una nueva estría corta y recta oblicua al resto y que no forma parte integral del conjunto inicial. A nuestro modo de ver se trata de una especie de tosca imitación del modelo original - en que las acanaladuras divergen poco a poco en una curva elegante-, haciendo un trazo recto independiente. Los casos que conocemos proceden de Almedinilla (núms. Inv. de Córdoba: 1.054, 1.055, 1.059, 62).

D. Disposición de las acanaladuras en la zona central de la boja: Mientras que en algunas piezas todas las acanaladuras forman un conjunto, en otras falcatas un grupo de líneas se separa de las demás y va a morir en el dorso de la hoja, justo en el punto en que comienza el filo dorsal (Fig. 2-C y 2-D). En este estudio se utiliza la siguiente convención:

\section{DISPOSICION \\ CENTRO DE LA HOJA}

I No es posible determinar si se abren o van paralelas.

II Una o varias se abren hacia el dorso.

III Se mantienen paralelas.

\section{TECNICA DE FABRICACION}

La técnica con que se realizaron las acanaladuras sobre las hojas de las falcatas no es apenas conocida, algo lógico si se tiene en cuenta el casi desierto científico que existe en lo referido a la tecnología metalúrgica empleada en las falcatas, pese a todas las generalizaciones que se han publicado a partir de las noticias que nos dan fuentes literarias. NIETO Y ESCALERA $(1970,30)$ comentan a propósito de una falcata de Almedinilla: 

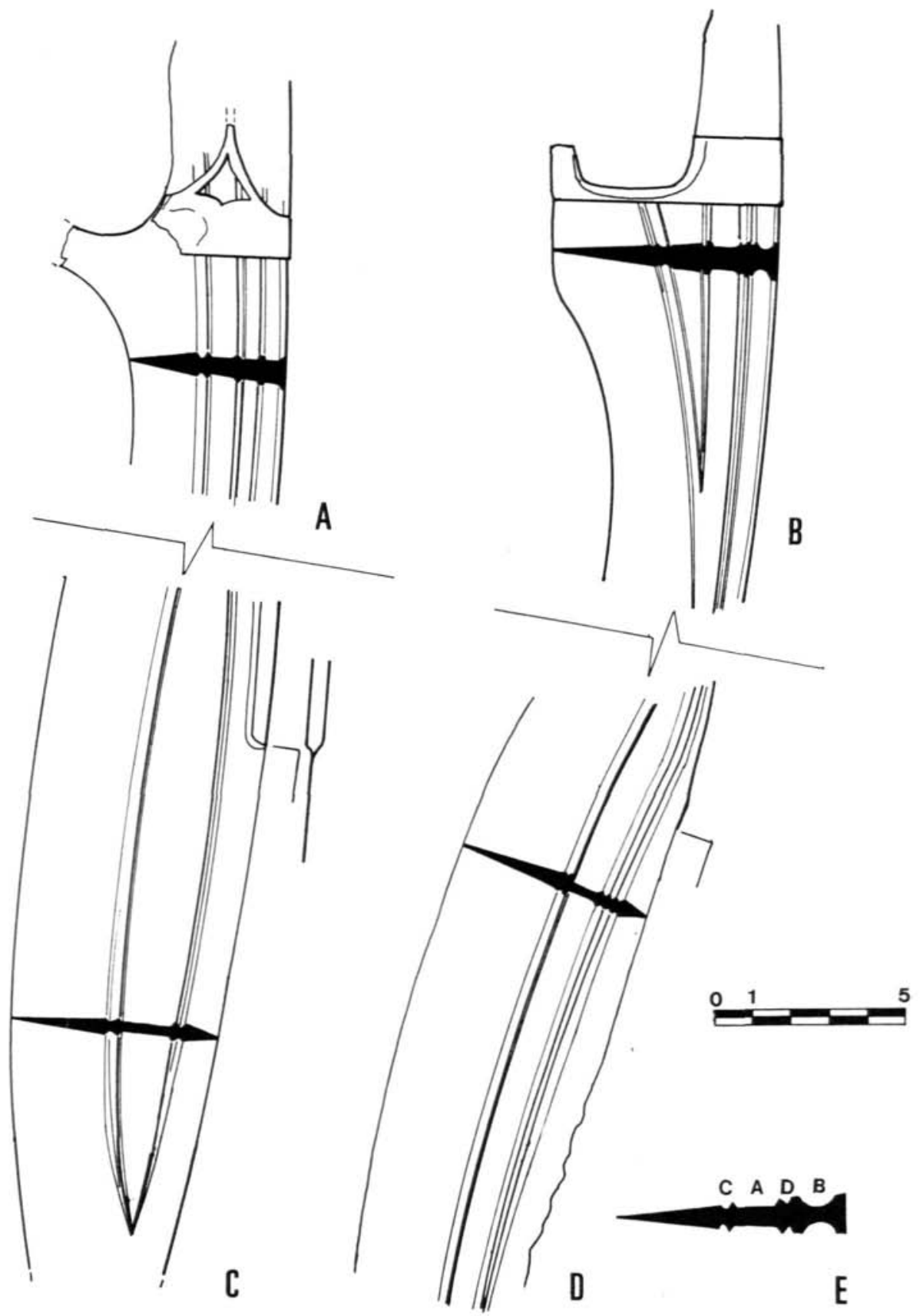

FIG. 2. - Tipos de acanaladuras en falcatas ibéricas. A-Tipo 1; B-Tipo 2; C-Tipo II; D-Tipo III; ETipos de sección de las acanaladuras. 
«Para el mejor conocimiento de la metalurgia de la pieza habría que estudiar la sección de la hoja (...) y fijar nuestra atención en las nervaduras, de gran perfección técnica, para las que hay distintas posibilidades de fabricación, que sólo se podrían confirmar con el estudio estructural de la sección".

Cabría en principio esperar que la técnica utilizada fuera la forja en caliente y martillazos, golpeando o presionando el hierro para producir canales y estrías, tal y como ocurre en otras espadas de hierro, como la gran acanaladura central de la hoja vikinga reproducida por Tylecote en su historia de la metalurgia europea (TYLECOTE, 1987, Fig. 7.18, pág. 265). Esta es también la hipótesis de la que partía Coghlan en el único análisis detallado que conocemos sobre este aspecto (COGHLAN, 1956-57, 169). Por tanto parecen sorprendentes los resultados obtenidos por este último autor en su estudio metalográfico de una falcata ibérica conservada en el Pitt Rivers Museum de Oxford. Según su análisis, las acanaladuras fueron practicadas cortando el hierro y no forjándolo, lo que le lleva a comentar:

"Cortar esta decoración no sería tarea sencilla incluso utilizando herramientas modernas, y sería interesante saber cómo una decoración de tan excelente calidad pudo ser cortada del hierro sólido usando las sencillas herramientas disponibles para un herrero de la Edad del Hierro".

Por si quedara alguna duda, en el análisis de una espada corta de antenas atrofiadas, procedente de Almedinilla y decorada con una característica serie de acanaladuras, se llega a idéntica conclusión: las mismas han sido cortadas y no forjadas (COGHLAN, 1956-57, 169 y 171).

Consultas realizadas a espaderos modernos y especialistas en armas blancas del Renacimiento nos han llevado a encontrar una tercera posibilidad, utilizada en armas más recientes, que nos parece con mucho la más razonable: las acanaladuras estrechas no son forjadas, pero tampoco cortadas limpiamente, sino que el hierro se extrae mediante cinceles cuando la hoja está todavía caliente, y antes del templado. Luego las acanaladuras y estrías así creadas se liman y pulen con cuidado (J. J. ALVAREZ Escribano, com. pers.).

\section{ESTUDIO DE LOS TIPOS}

Para el estudio que estamos realizando hemos seleccionado una muestra de 301 falcatas, procedentes de los siguientes yacimientos: Almedinilla (Córdoba); Illora (Granada); Cabezo del Tio Pío, Cabecico del Tesoro, Cigarralejo, Coimbra del Barranco Ancho y Los Nietos (Murcia); Casa del Monte, El Amarejo, El Tesorico de Hellín, Hoya de Santa Ana, Llano de la Consolidación (Albacete); El Charpolar, Isleta de Campello, La Albufereta y Novelda (Alicante). Somos conscientes de que existen muchas más falcatas, y de que la muestra se concentra en el Sureste de la Península, pero creemos que 301 armas es cantidad suficiente para un primer análisis, y por otra parte la concentración geográfica responde a una concentración real de la distribución conocida de la falcata ibérica: fuera de esta zona la falcata es un arma casi exótica (Ver Tablas 1-3). 
De las 301 falcatas estudiadas, sólo en dos casos (Cabecico del Tesoro, Sep. 190 y Sep. 41) es probable que las hojas no fueran acanaladas, aunque la seguridad es imposible, pues si las acanaladuras fueron muy superficiales - contrariamente a la práctica habitual-, pueden haberse perdido por la corrosión.

En otros 129 casos no nos ha sido posible determinar si la falcata está acanalada o no, por diversas razones (la pieza se ha perdido o sólo se conserva un fragmento de la empuñadura o de la punta; la ilustración publicada es imprecisa).

En todos los demás casos (170 falcatas, $56,5 \%$ del total) con seguridad hay acanaladuras. Ahora bien, bastantes de estas falcatas no están completas o se hallan muy corroidas. En general, no es posible utilizar el criterio "Número de Acanaladuras» (Apdo. I.A.) porque éste puede variar a lo largo de la hoja; ni tampoco el de "Forma de las acanaladuras" (Apdo. I.B.) porque normalmente las piezas no tienen un estado de conservación apropiado. En cambio, en general sí es posible distinguir los tipos según los criterios I.C. y I.D., aunque no necesariamente ambos en la misma pieza, sobre todo cuando está rota. Por ello trataremos primero la forma de las acanaladuras junto a la empuñadura y luego en el centro de la hoja.

\section{Criterio I.C. (Disposición de las acanaladuras junto a la empuñadura)}

Puede observarse en un total de 107 falcatas. De ellas, 38 (35,5\%) son del tipo 1 (las acanaladuras divergen al llegar a la empuñadura) y $69(64,5 \%)$ del Tipo 2 (las acanaladuras siguen paralelas). Esto significa que la solución más sencilla es también la más frecuente.

No se aprecia un predominio de un tipo u otro según la zona geográfica (Almedinilla en Córdoba tiene un 29,5\% de sus piezas del tipo 1 y un $71 \%$ del tipo 2; Cigarralejo en Murcia tiene un $34 \%$ del Tipo 1 y un $66 \%$ del Tipo 2. Estos porcentajes coinciden con los globales, lo que significa que la divergencia o no de las acanaladuras en la empuñadura no depende de la ubicación geográfica, al menos entre el Sureste y la Alta Andalucía.

Tampoco parece haber una relación obvia entre el tipo de empuñadura (de cabeza de ave o de caballo) y el tipo de acanaladura. Entre las falcatas del tipo $1,7(18,4 \%)$ son de cabeza de ave, 19 (50\%) de cabeza de caballo y en $12(31,6 \%)$ casos la empuñadura se ha perdido. De las falcatas del Tipo 2, 20 (30\%) son de cabeza de ave, $23(33,3 \%)$ de caballo y $26(37,7 \%)$ indeterminadas. A la inversa, de la 27 falcatas de cabeza de ave cuyas hojas tenían acanaladuras reconocibles, un $74,9 \%$ eran del tipo 2 (acanaladuras paralelas) y sólo un $25,9 \%$ del tipo 1 . De las de cabeza de caballo, un 53,5\% tenía acanaladuras paralelas y un $46,5 \%$ divergentes (Fig. 3.A.). Por tanto existe una tendencia marcadda a que las falcatas de cabeza de ave tengan las acanaladuras paralelas. Las implicaciones de tipo cronológico que esto pudiera tener las veremos en el Apartado IV.

Criterio I.D. (Disposición de las acanaladuras respecto al dorso de la hoja)

Puede ser estudiada en un total de 99 piezas. De ellas, $76(76,8 \%)$ mantienen las acanaladuras paralelas hasta el final, mientras que en 23 falcatas ( $23,2 \%$ ), una o varias acanaladu- 

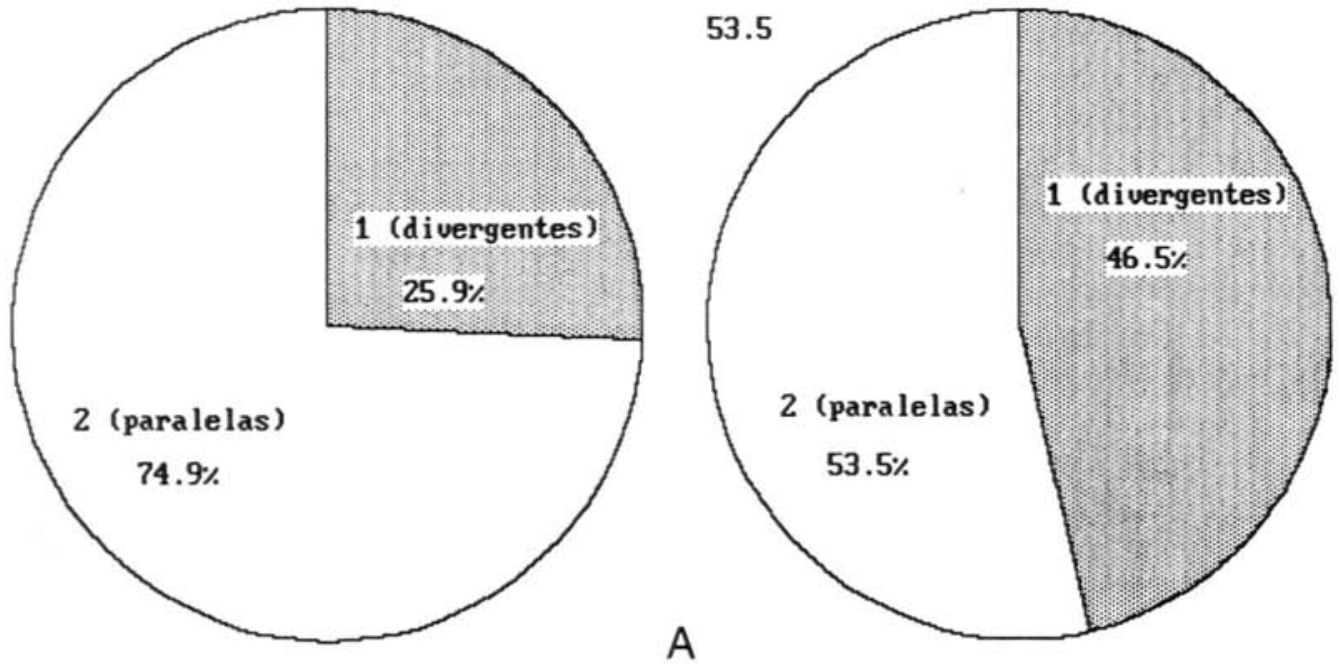

CABEZA DE AUE

CABEZa DE CABALLO
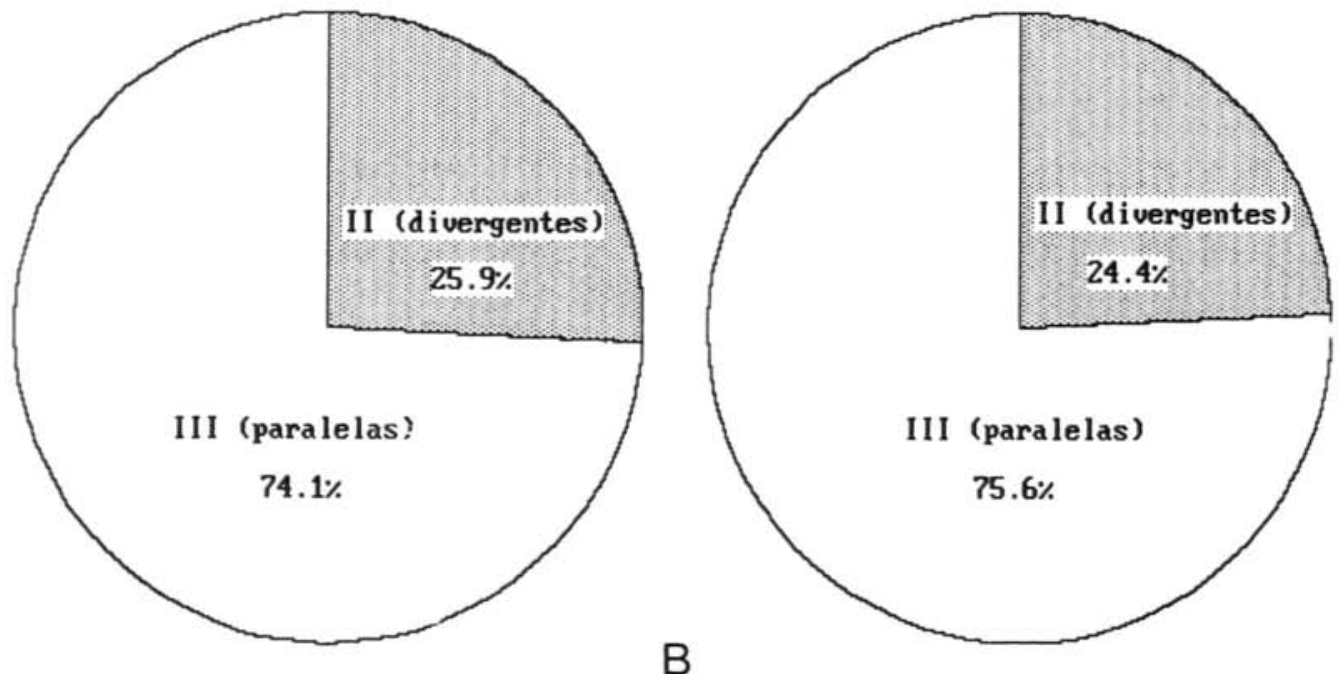

FIG. 3. - Distribución de los tipos de acanaladuras según el tipo de empuñadura. A-Disposición de las acanaladuras junto a la empuñadura; B-Disposición en el centro de la hoja. 
ras se separan del resto y van a morir en el dorso de la hoja, justo donde comienza el doble filo. Como prácticamente todas las falcatas estudiadas tienen filo dorsal, conviene recordar que esta variante de acanaladuras no se debe a la existencia de filo, sino que es independiente del mismo. Por tanto, la variante más sencilla vuelve a ser la más frecuente.

Por lo que se refiere a la distribución geográfica, observamos que en Almedinilla e Illora (Andalucía Occidental) un $80 \%$ de las falcatas son del tipo III (acanaladuras paralelas), y un $20 \%$ del tipo II (divergentes), mientras que en Murcia un $72,5 \%$ son del tipo III y un $27,5 \%$ son del II. Los datos para Albacete y Alicante son demasiado escasos para ser significativos. La coincidencia de estos porcentajes con las cifras globales indica que no hay una razón geográfica en la diferenciación de los tipos.

En cuanto a la posible relación entre el tipo de empuñadura y el tipo de acanaladura, se puede observar que, entre las falcatas de tipo III (acanaladuras paralelas), un total de 20 (26\%) son de cabeza de ave, 31 (41\%) de cabeza de caballo, mientras que otras 25 (33\%) son indeterminadas. De las falcatas de tipo II (acanaladuras divergentes), 7 (30,4\%) son de cabeza de ave, $10(43,5 \%)$ de cabeza de caballo, y $6(26,1 \%)$ indeterminadas. A la inversa, de entre 27 falcatas de cabeza de ave en las que se ven bien las acanaladuras de la hoja, un $74,1 \%$ tienen acanaladuras de tipo III, y sólo un $25,9 \%$ del tipo II. De las falcatas de cabeza de caballo, un $75,6 \%$ tiene acanaladuras del tipo III y un 24,4\% del tipo II (Fig. 3-B). No hay pues una relación entre el tipo de empuñadura y el de acanaladura en el centro de la hoja.

Nos resta examinar si hay algún tipo de relación entre el tipo de acanaladura en la zona de la empuñadura y en la zona de la hoja. En síntesis, el resultado es el que sigue: hay 83 falcatas en las que sea posible determinar la forma completa de las acanaladuras. De ellas, en 38 casos las acanaladuras son paralelas desde el principio al final, y de estas falcatas, 12 son de cabeza de ave, 12 de caballo y 14 indeterminadas.

Otras 23 falcatas tienen acanaladuras divergentes junto a la empuñadura y paralelas en el centro de la hoja; 16 las presentan paralelas junto a la empuñadura y divergentes en la hoja, mientras que sólo 6 falcatas tienen las acanaladuras divergentes tanto en el centro de la hoja como junto a la empuñadura. Estas combinaciones de caracteres no se agrupan en áreas geográficas determinadas.

De todas formas, en un nivel más complejo de análisis podría ser rentable realizar una matriz de similitud y a partir de ella un análisis de agrupamiento mediante dendrogramas para observar la forma en que estas características se ordenan. Por ahora, sin embargo, hemos decidido conscientemente detenernos en este nivel de análisis hasta reunir una muestra aún mayor de falcatas, agotar las posibilidades de la estadística descriptiva más simple e incluir en esa matriz un número mayor de variables como la presencia o ausencia de filo dorsal, ángulo axial, etc. (QUESADA, 1989, Vol. I, 258 ss.).

\section{CRONOLOGIA}

En párrafos anteriores hemos podido comprobar que se producen todas las combinaciones posibles de empuñaduras y tipos de acanaladura, y que en ningún caso una asociación 
predomina claramente o es despreciable. También hemos visto que no parecen ser razones geográficas (al menos en el área que estas falcatas abarcan) las que determinan los distintos tipos: las combinaciones se producen en los distintos yacimientos. Cabe por tanto suponer que las diferencias sean debidas a razones cronológicas, y que alguna o algunas de las variantes sean más antiguas que las demás.

En esta línea han trabajado ya distintos autores, pero siempre con análisis puramente intuitivos, sin estudiar muestras amplias y sin poder fechar las piezas más que por vagas consideraciones estilísticas fundadas en las piezas mismas y sin contextos arqueológicos fiables. Por ello se han propuesto líneas evolutivas producto más del deseo de ordenar la información que resultado de un trabajo detallado sobre el material.

Así por ejemplo, en 1913 Sandars opinaba que algunas características de las falcatas evolucionaban en un cierto sentido. Por ejemplo, las barras macizas de cierre de la empuñadura evolucionarían en cadenillas (SANDARS, 1913, 35) y el filo simple inicial acabaría convirtiéndose en doble filo en manos de los iberos (1913, 36). M. E. CABRÉ (1934, passim) opinaba que el tipo de cabeza de caballo evolucionó desde el de ave, y que las acanaladuras más antiguas son paralelas en su arranque (de nuestro Tipo 2) y las más recientes son divergentes (Tipo 1) y más numerosas. Al revés que Sandars, cree Cabré que el cierre de las empuñaduras era inicialmente de cadenilla y que sólo al final de su serie A empiezan a aparecer las barras macizas.

Sólo nos fijaremos por ahora en la opinión de M. E. Cabré en el sentido de que las acanaladuras paralelas junto a la empuñadura son más antiguas. En un reciente trabajo de E. Cuadrado - ceñido al estudio de armas del Cigarralejo-, que aprovecha la excelente datación de muchas de las sepulturas, se llega a la conclusión de que entre el 425 a. C. y el s. I a. C. no parece haber diferenciación cronológica por este detalle, sino que desde fases antiguas se dan los dos modelos (CUADRADO, 1989, 13). A la luz de la información de que nosotros disponemos, ésta parece ser la conclusión más correcta puesto que ya desde finales del s. V. a. C. vemos aparecer acanaladuras divergentes junto a la empunadura (Cigarralejo, Sep. 277), proceso que continúa a lo largo de todo el s. IV a. C. Los resultados que podemos mostrar, sin embargo dependen mucho de la cronología del Cigarralejo, pues en los otros grandes yacimientos que hemos utilizado no hay contexto para datar las armas (Almedinilla, Illora) o éstas aparecen a menudo casi destruidas (Cabecico del Tesoro, Albufereta). Ciertamente, la comparativa escasez de falcatas bien conservadas de época tardía nos impide saber con seguridad si las falcatas de Tipo 2 (paralelas) aparecen con frecuencia a partir del s. III a. C.

Por lo que se refiere a la divergencia o no de las acanaladuras en la parte central de la hoja, nuestra conclusión es la misma que en el caso anterior: hay piezas de ambos tipos a lo largo de todo el período que va desde finales del s. V a finales del III a. C.

En el apartado anterior describimos la frecuente asociación de falcatas de cabeza de ave con acanaladuras paralelas del tipo 2, en una combinación que según las hipótesis de $\mathbf{M}$. E. Cabré revestiría mayor antigüedad que otras variantes. En realidad, nosotros no hemos podido confirmar o refutar estadísticamente esta hipótesis por falta de un número suficiente de falcatas bien conservadas que pertenezcan a épocas tardías. En efecto, sí sabemos que hay falcatas de cabeza de caballo y acanaladuras divergentes en fases antiguas, lo que indica que ambos tipos conviven desde el principio (algo que contradice la reconstrucción de Cabré). 
Lo que no sabemos es si el tipo de "cabeza de ave" con acanaladuras divergentes se extingue pronto, dejando solamente la variante de "cabeza de caballo". Aunque hay ejemplares aislados con acanaladuras paralelas o cabeza de ave en fechas avanzadas, la asociación observable de ambas características y en armas datadas en Baja Epoca no se produce en ninguna de la falcatas que hemos estudiado. La cuestión, por tanto, sigue debatible.

Las representaciones escultóricas no nos ayudan demasiado. Es claramente divergente (Tipo 1) el patrón de las acanaladuras de la falcata que porta uno de los guerreros de Osuna (Lám. I-A), perteneciente a un conjunto fechable en Baja Epoca Ibérica, quizá a mediados del s. II a. C. (León, 1981, 189); pero también son del mismo tipo las acanaladuras de una escultura, con seguridad más antigua, procedente de La Alcudia de Elche (Ruano, 1987, III, 530-532 y I, 477), fechable en el s. IV a. C. si no antes (Lám. I-B).

Es cierto que nos movemos en un margen cronológico relativamente reducido, entre finales del s. V y mediados del II a. C. Todo lo que hasta ahora llevamos visto nos hace pensar que durante estos 250 años no se modifica apenas el aspecto externo de la falcata ibérica - al menos en los caracteres formales estudiados en este artículo-. Da la impresión de que desde el momento en que la falcata es adoptada como arma, hacia mediados del s. V. a. C. o quizá algo antes (QUESADA, e. p.), sus características formales están ya plenamente definidas, y desarrolladas las distintas opciones disponibles en la forma de la empuñadura o de las acanaladuras. Es posible sin embargo que algunas de las combinaciones (empunaduras en cabeza de ave y acanaladuras paralelas junto a la empuñadura) desaperezcan antes que otras que perviven hasta el final.

Todo ello nos obliga a dar - siquiera brevemente - un salto atrás en el tiempo y en el espacio para determinar la existencia o no de acanaladuras en el probable prototipo de la falcata: la machaira itálica (y no la machaira griega, como hemos tratado de demostrar en otro lugar, ver QUESADA, e. p.). El número de piezas itálicas conocidas sobrepasa algo la treintena, de las que casi ninguna ha sido publicada con dibujos o fotografías detalladas. Aún así, sin embargo, la información disponible permite llegar a la conclusión de que las profundas acanaladuras presentes en la falcata ibérica, con las distintas variantes que venimos estudiando, están ausentes de las machairas itálicas $-\dot{y}$ también de las griegas.

Sólo en dos casos, de entre la media docena de piezas que hemos podido estudiar personalmente, aparecen unas finas incisiones realizadas con una especie de peine, de función claramente decorativa pues apenas arañan el metal. En la machaira de GUALDO TADINO (Mus. de Villa Giulia) apenas son visibles (Fig. 4-B), pero en la pieza de BOMARzo (Mus. Gregoriano Etrusco, N. Inv. 12.327) se aprecia perfectamente la existencia de dos series de estrías toscamente empalmadas (Fig. 4-A). Desde la base de la empuñadura hasta la mitad de la hoja hay cuatro estrías, y desde allí y hasta el extremo, seis. Son paralelas entre sí y respecto al dorso de la hoja, y llegan hasta la misma punta - otra diferencia con las acanaladuras de las armas ibéricas, que suelen morir a unos $12 \mathrm{cms}$. del extremo-, no divergen en ningún punto hacia el dorso, y tampoco tienen la elegante composición de las acanaladuras ibéricas que se ensanchan o adelgazan al ritmo de la propia hoja.

La existencia de estas incisiones, así como la representación de las mismas en vasos áticos de figuras rojas, nos hace sospechar que muchas de las piezas itálicas y griegas pobremente 

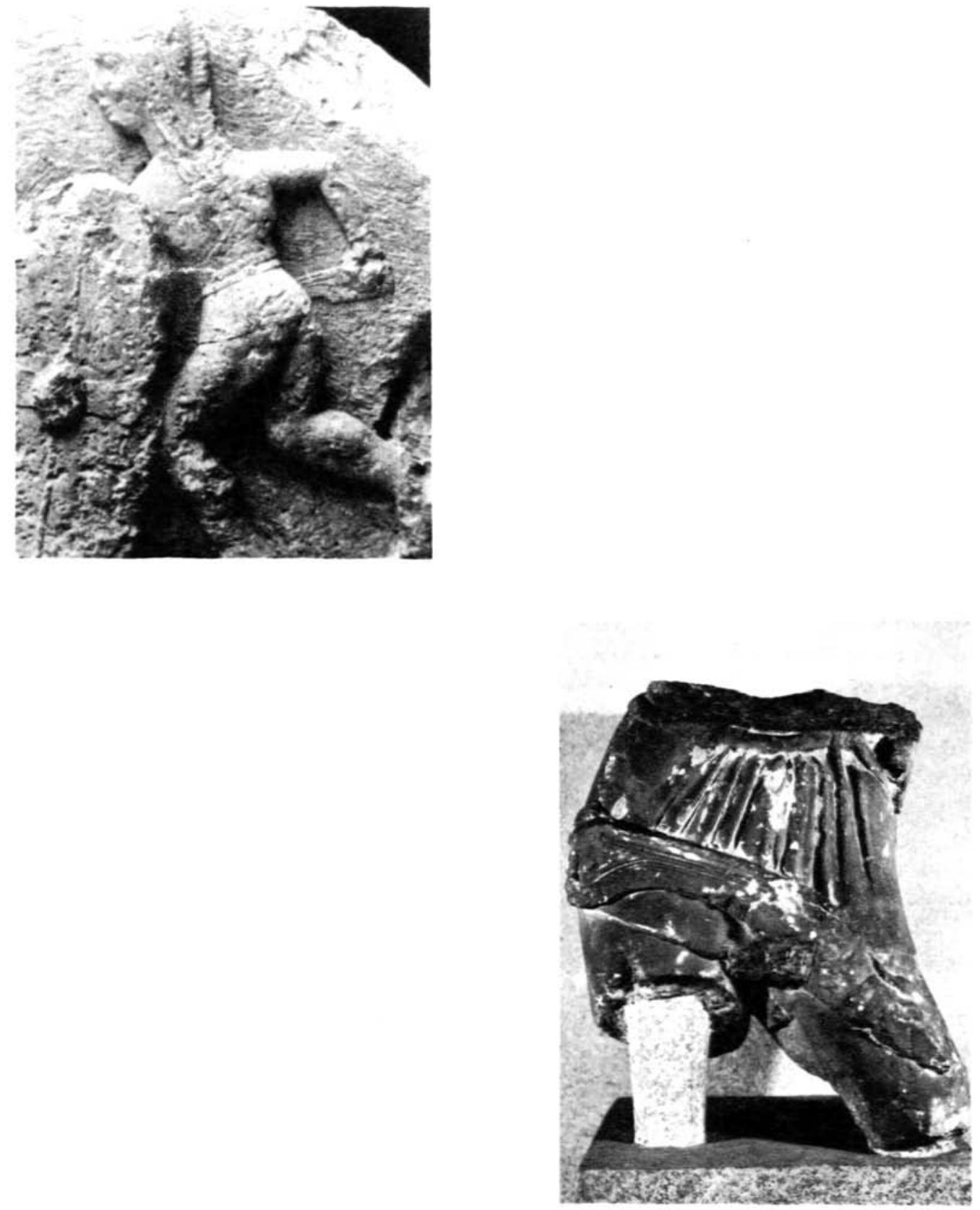

LAM. I-A. - Relieve de Osuna (Sevilla); B.-Escultura de guerrero procedene de La Alcudia de Elche (Alicante). 


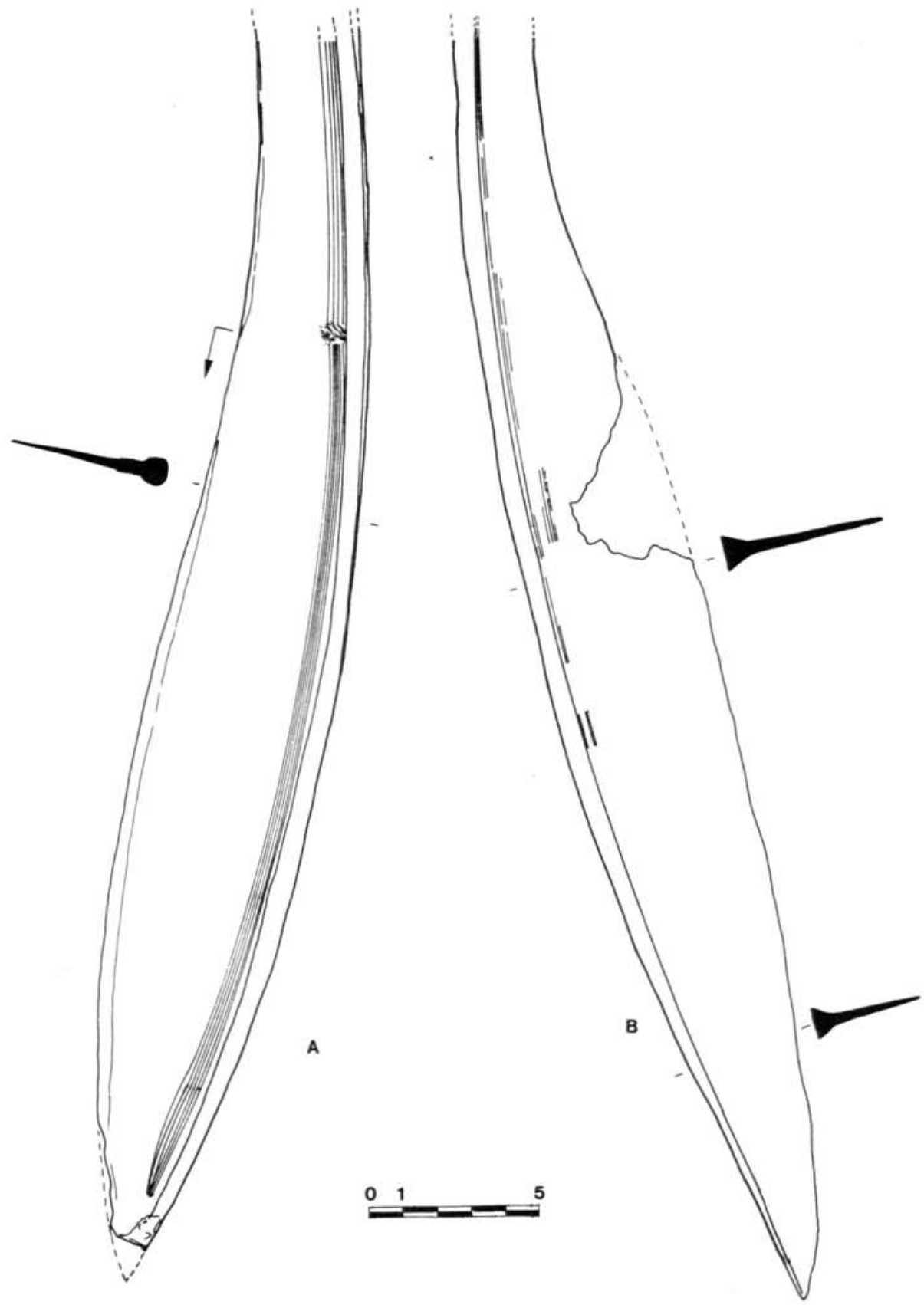

FIG. 4. - Estrías en machairas itálicas. A-Mus. Gregoriano Etrusco Vaticano. N. Inv. 12.327. ¿Bomarzo?. B-Mus. Villa Giulia, Roma. Gualdo Tadino. 
publicadas - algunas de ellas perdidas - deben tener también estrías similares. Lo importante es señalar que se trata de un sistema mucho más elemental que el empleado en las armas ibéricas, que cuando aparece en la Península está ya, como en otros aspectos, plenamente formado con una delicadeza y complejidad mucho mayores que la de sus prototipos.

\section{LA FUNCION DE LAS ACANALADURAS}

Aparte de las consideraciones puramente tipológicas y de su empleo para realizar clasificaciones descriptivas y ordenaciones cronológicas de las variantes, el otro aspecto a tener en cuenta en el estudio de las acanaladuras es el de su posible función.

En síntesis, se han expresado hasta ahora tres hipótesis, no excluyentes entre sí. Algunos autores - los que más recientemente han tocado el tema- consideran que las acanaladuras están diseñadas con el objetivo de agravar las heridas una vez que el arma penetra en el cuerpo del enemigo (BLÁZQUEZ y GarCía GELABERT, 1989, 108; CUADRADO, 1987, 84; CUA. DRADO, 1989, 13). Esta es la versión comúnmente admitida y, aunque normalmente no se especifique la razón de ese agravamiento de las heridas, los argumentos que se dan hablan de "entrada de aire en la herida y con él de bactarias contaminantes", "gangrena gaseosa", "trombosis", etc.

En segundo lugar, se ha considerado que el conjunto de acanaladuras tiene una función puramente decorativa. Así lo han expresado investigadores como COGHLAN $(1956-57,169)$ o LATORRE (1979, 161).

Finalmente Sandars, en su The Weapons of the Iberians (SANDARS, 1913,35) añade al factor estético otro práctico: las acanaladuras se efectúan para aligerar la hoja.

A nuestro modo de ver (QUESADA, 1989, vol. I, 256-258) no cabe ninguna duda de que la razón de ser de las acanaladuras es aligerar la hoja sin disminuir su resistencia, como lo ha sido a lo largo de toda la historia de las armas blancas. Si además estas acanaladuras se realizan con gracia y cuidado, alcanzan un valor estético que mejora el aspecto del arma.

Curiosamente, es en trabajos antiguos, escritos por autores conocedores de la técnica de las armas y de su uso, donde se defiende con mejores argumentos el papel decorativo y sobre todo la función aligeradora de las acanaladuras. Si un ingeniero como Sandars zanja directamente la cuestión aludiendo al carácter decorativo de las mismas, poco antes de embarcarse en el primer análisis metalográfico de una falcata (SANDARS, 1913, 35), será un militar, esgrimista, viajero y escritor como R. F. Burton, escribiendo en el tercer cuarto del s. XIX, quien proporcionará una explicación completa y clara del papel de las acanaladuras en su obra "The Sword" (BURTON, 1884, 131-136).

Burton especifica que la función de las acanaladuras es aligerar el arma por un lado, y por otro evitar el exceso de flexibilidad de la hoja manteniendo e incluso aumentando la resistencia. Las acanaladuras estrechas y profundas son preferibles a las anchas y superficiales, porque el principio mecánico es similar a tratar de aplastar un arco sobre su clave: cuanto más apuntado el arco, mayor resistencia a la presión.

El principio es el mismo aplicado a nuestras modernas vallas de aluminio: para evitar que se doblen se practican unas acanaladuras que dan una sección quebrada. Tratar de do- 
blar una de esas vallas en el sentido de los nervios y acanaladuras es extremadamente difícil mientras que si fuera una lámina lisa resultaría muy sencillo. De la misma forma, una espada con acanaladuras resulta mucho más difícil de doblar lateralmente, aunque ello no significa que se pierda toda la flexibilidad, imprescindible en un arma de guerra diseñada para soportar golpes bruscos.

Por lo que se refiere al aligeramiento, todos los expertos que hemos consultado coinciden en que la ligereza de un arma que se ha de blandir durante un período prolongado es fundamental, siempre que no se pierda resistencia y capacidad de penetración. En una falcata, la anchura del dorso proporciona peso suficiente para dar potencia al golpe, mientras que el tamaño y profundidad de las acanaladuras indica claramente que una buena cantidad de metal ha sido retirada sin disminuir la resistencia de la hoja.

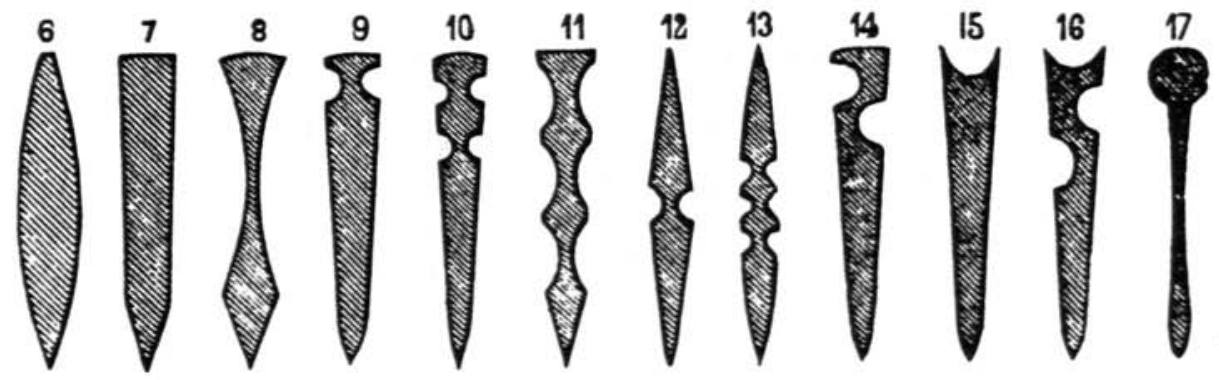

FIG. 5. - Tipos de acanaladuras en hojas de espada. Tomado de BURTON (1884), Fig. 118.

Burton proporciona una figura, que aquí recogemos (Fig. 5), comentando las ventajas y desventajas de distintos tipos de sección de arma blanca de guerra. La número 10 , similar a la de una falcata, sale bien parada en la ecuación peso-resistencia-potencia. En cambio, la número 17, durante algún tiempo hoja de reglamento en el ejército inglés (la "ramrod back" o «dorso de baqueta»), es muy poco eficiente porque la hoja resulta demasiado delgada en comparación con el grueso dorso, lo que hace muy difícil un templado regular. Curiosamente, esta poco eficiente sección decimonónica coincide con la de las más antiguas machairas italo-griegas, precedentes de la ibérica, que como hemos visto apenas poseen unas finas estrías que no eliminan metal y en cambio tienen un grueso nervio en el dorso (Fig. 4). Puede, pues, que el menos eficiente modelo inicial fuera modificado por los iberos eliminando el rígido y pesado nervio dorsal y ampliando las acanaladuras, con el resultado de conseguir una espada más ligera y a la vez más resistente, más fácil de templar y más elegante.

Vamos ahora a examinar las razones que puedan justificar el diseño de las acanaladuras como sistema de agravar las heridas infligidas al enemigo. Desde un punto de vista médico, la utilidad, aunque factible no es tan general ni evidente. Ya Burton apunta con escepticismo (BURTON, 1884, 136) esta posibilidad, pero no referida a las acanaladuras, sino a una moda de los siglos XV y XVI consistente en decorar la hoja con calados: 
«Hay otras formas de aligerar las hojas además de acanalarlas. Una moda favorita en los siglos XV y XVI, la Edad de Oro de la espada, fue romper la continuidad mediante calados, que daban juego a la imaginación del ornamentador. También se suponía que haría más peligrosa la herida al permitir la entrada de aire.

Según las consultas que hemos podido realizar, una herida punzante (en general más grave que una cortante) no se hace necesariamente más grave por la entrada de aire si se produce en tejidos, y desde luego las infecciones no se producen porque en el momento de introducir la hoja entre aire, ni este aire puede producir gangrena gaseosa (dos de las explicaciones al uso). El cambio, si la hoja interesa la cavidad pleural, la entrada de aire sí puede producir un neumotórax, con el consiguiente agravamiento de la herida. De la misma manera, si la herida afecta a una arteria o vena gruesa, la entrada inmediata de aire puede provocar una embolia gaseosa de efectos fulminantes.

Ahora bien, para que estos desagradables efectos puedan tener lugar, la herida no se debe cerrar sobre la hoja cuando ésta penetre y, más importante aún, la acanaladura debe llegar hasta el extremo de la hoja para que pueda comunicar con el aire exterior. Sin embargo, las espadas renacentistas — cuyas acanaladuras sirven de campo para la inscripción de lemas y nombres - rara vez presentan estrías de más de $30 \mathrm{cms}$. de longitud midiendo desde la empuñadura, con lo que difícilmente pueden ayudar a introducir aire.

Del mismo modo, vamos a tratar de demostrar que las acanaladuras de las falcatas no se diseñaron pensando en agravar las heridas. Las acanaladuras se sitúan siempre junto al dorso de la hoja, de forma que la mayoría de los golpes cortantes deberían penetrar al menos $5 \mathrm{cms}$. hasta que la acanaladura llegara al contacto con la superficie de la herida, e incluso en este caso ello no garantiza la penetración de aire hasta el fondo de la misma, donde podría resultar peligroso. Ahora bien, si un sablazo penetra como mínimo $10 \mathrm{cms}$. en un cuerpo humano - para que el aire pueda entrar dentro de la herida - el peligro añadido de la entrada de aire parece despreciable. Puede objetarse que las acanaladuras se diseñan en función de las heridas punzantes, donde la posibilidad de herir un órgano interno vital es mayor. En este caso el problema es el mismo, porque las acanaladuras nunca llegan hasta la punta, sino que mueren a una distancia media de $12 \mathrm{~cm}$. de la punta (Fig. 6; muestra analizada, 50 piezas de Almedinilla, Cabecico del Tesoro y Cigarralejo; valor máximo $=20 \mathrm{cms}$; valor mínimo, 5 cms.; distribución estadísticamente normal). Si una espada de la anchura de la falcata penetra un mínimo de $12 \mathrm{cms}$. en un cuerpo - y el doble para que las acanaladuras lleguen al interior del mismo-, es ocioso por superfluo que entre o no aire, porque un tórax queda atravesado de parte a parte.

Es nuestra opinión que los iberos no conocieron, ni intuitiva ni científicamente, la posibilidad de agravar heridas punzantes o cortantes permitiendo que una mayor cantidad de aire entrara en la herida en el momento del golpe. La opinión al uso en este sentido nos recuerda la situación narrada por E. M. REMARQUE en su famosa novela Sin novedad en el Frente, cuando se describe la ira de los soldados aliados ante un tipo de bayoneta alemana con filo serrado en el dorso, que creían diseñado para agravar las heridas con ella causadas. En realidad se trataba de un arma-útil diseñada pensando en actividades de zapadores e ingenieros. Por otro lado, y según las consultas que hemos podido realizar con especialistas en 


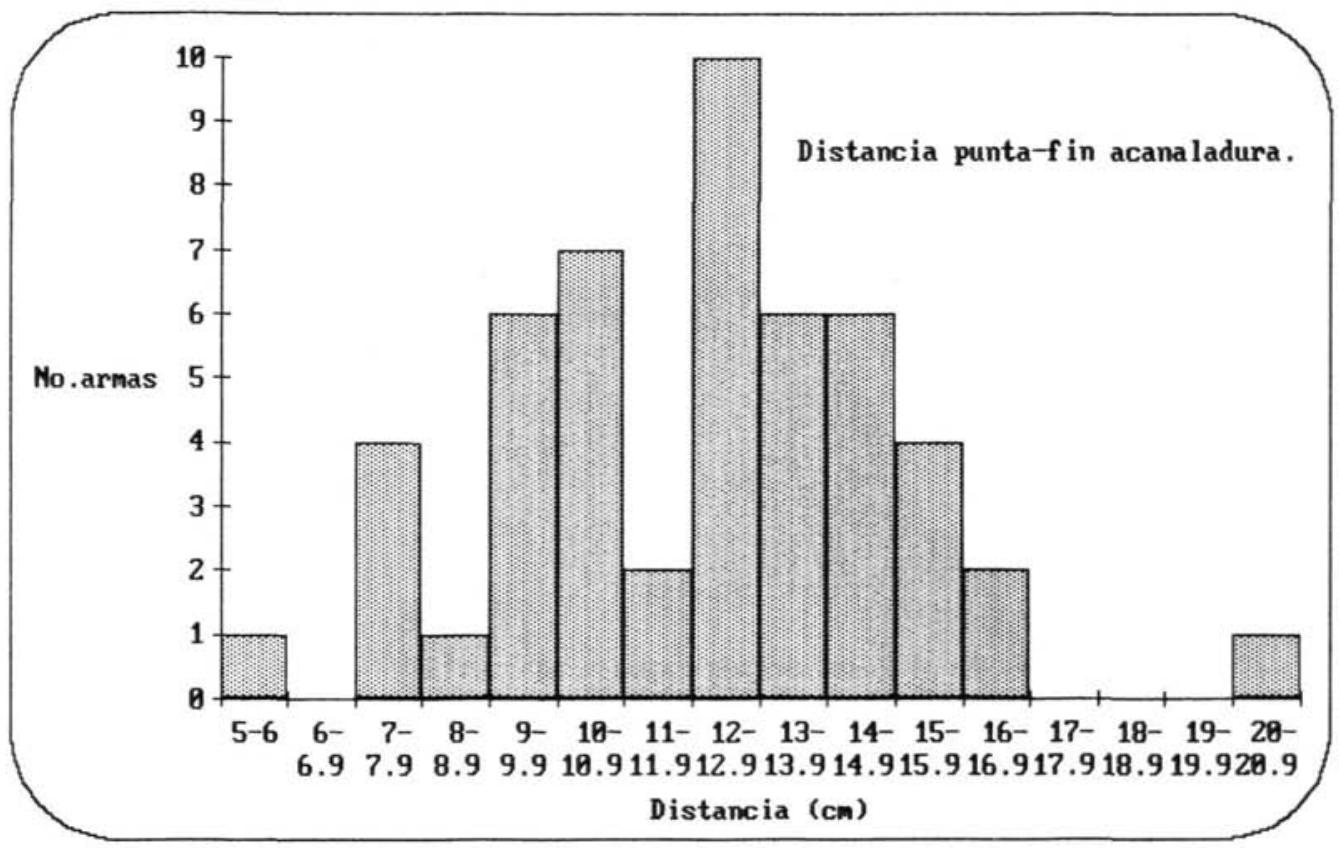

FIG. 6. - Distribución de distancias desde el final de las acanaladuras hasta la punta en una muestra de 50 falcatas ibéricas.

armas de otros períodos, ni en la Edad Media (A. SOLER DEL CAMPO, com. pers.) ni en la Moderna (J. J. ALVAREZ ESCRIBANO, com. pers.) se utiliza como argumento para la realización de acanaladuras la entrada de aire, y sí la ligereza y la decoración.

Por todas estas consideraciones creemos que la razón por la que los herreros y artesanos ibéricos diseñaron falcatas con acanaladuras en la forma en que lo hicieron fue mejorar las cualidades de resistencia, ligereza y flexibilidad de las armas, además de mejorar su estética. Este último aspecto es evidente si se contempla el cuidado con que se realizaron las acanaladuras, la forma en que éstas se adaptan al perfil, cómo se ensanchan en la zona central, cómo se abren con gracia junto a la empuñadura, etc. Todo esto evita la monotonía de una gran superficie plana como la que tendría la hoja de la falcata si no existieran acanaladuras. Esta función decorativa se refuerza si consideramos que a menudo los damasquinados en plata en las falcatas que tienen decoradas sus hojas siguen en su desarrollo la línea de las acanaladuras, reforzando su efecto plástico mediante el color blanco de la plata que contrasta con el fondo oscuro del metal (Lám. II). Que la función estética no es la única se comprueba por la profundidad que tienen las acanaladuras, muy superior a la de una mera incisión, y que retiran una no despreciable cantidad del hierro de la hoja. 

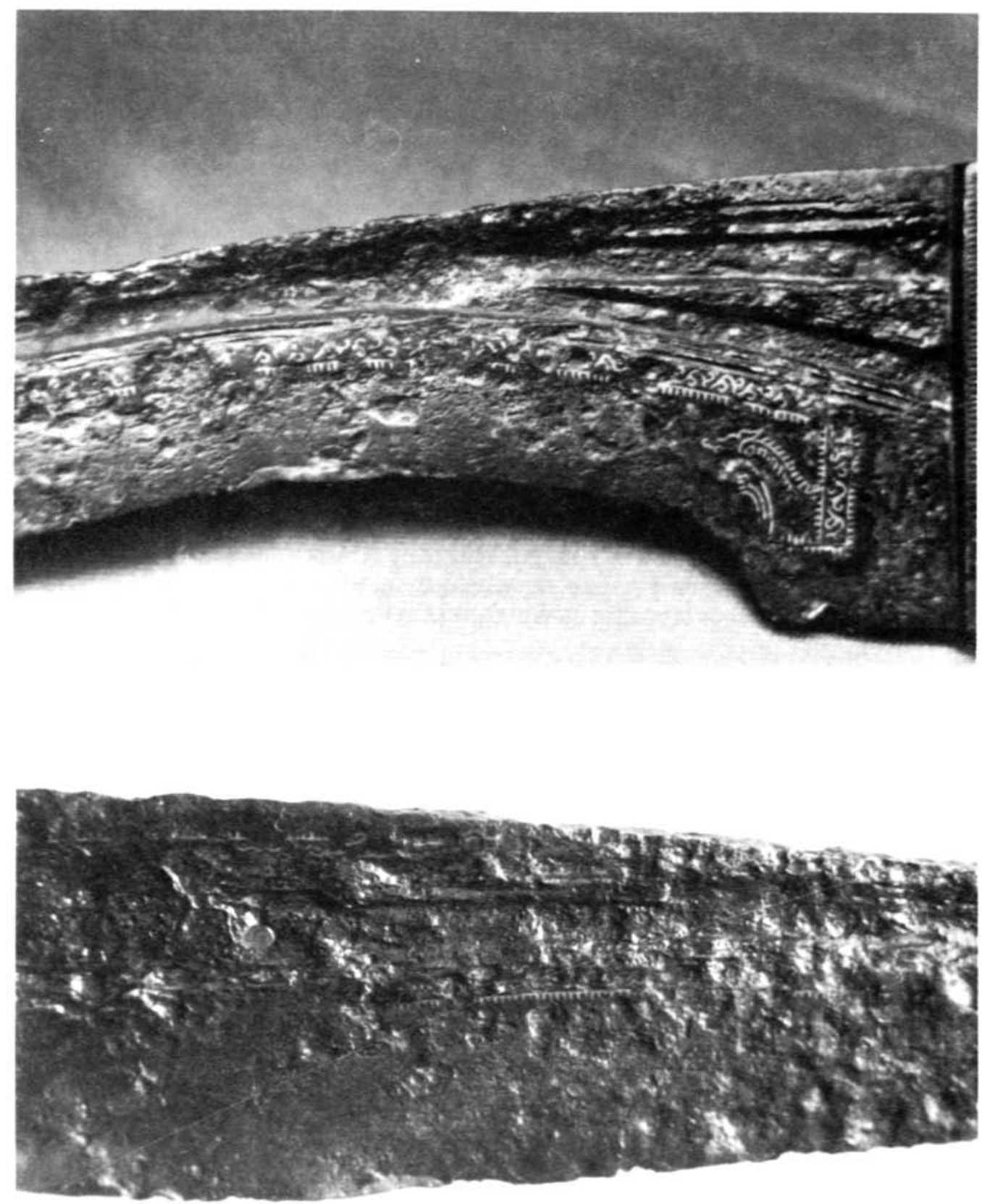

LAM. II. - Relación de la decoración damasquinada en plata con las acanaladuras en una falcata procedence de lllora (Granada). Fotos López Grande 


\section{CONCLUSIONES}

En resumen, hemos recogido en este artículo los criterios descriptivos que utilizamos en nuestro estudio de las acanaladuras de las falcatas, que consideramos mínimos para una adecuada descripción y publicación de las mismas. También hemos recogido la —escasa - información disponible sobre la técnica con que fueron realizadas, como base para un ulterior estudio metalográfico.

No parece que las diferencias morfológicas en las acanaladuras respondan a dos zonas de producción distintas - Andalucía y Sureste - Tampoco se aprecia, utilizando una muestra de 300 armas procedentes de una quincena de yacimientos de Andalucía Occidental, Sureste y Levante, una evolución diacrónica de distintos tipos, aunque hay algunas posibilidades que pueden todavía considerarse - por ejemplo, que las falcatas con empuñadura de cabeza de ave y acanaladuras completamente paralelas sean antiguas y no perduren en Baja Epoca- Parece que todas las variantes de acanaladura coexisten ya desde finales del siglo $\mathrm{V}$ (las falcatas aparecen plenamente formadas ya en este período), aunque el diseño de las acanaladuras - y en general el de las armas completas - presenta sustanciales mejoras respecto a sus prototipos itálicos. Estas mejoras se refieren a la desaparición del nervio dorsal y a la conversión de las finas estrías en acanaladuras anchas y profundas.

Desde el punto de vista de la funcionalidad, nos parece claro que las acanaladuras no se diseñaron con la intención de agravar las heridas causadas por el arma, sino que el objetivo es distinto y triple: aligerar la hoja sin perjuicio de la resistencia; limitar la flexibilidad de la misma en sentido lateral y crear un efecto decorativo agradable, factor este último en modo alguno despreciable si tenemos en cuenta que la falcata es tanto un arma de guerra como un símbolo de poder y prestigio social. 
TABLA 1

\begin{tabular}{|c|c|c|c|c|c|c|}
\hline YACIMIENTO & SEP & Fich. & N. INV & TIPO & ACANAL & DATACION \\
\hline ALMEDINILLA & & $\begin{array}{l}868 \\
879 \\
882 \\
888 \\
891 \\
892 \\
897 \\
901\end{array}$ & $\begin{array}{r}1055 \\
1058 \\
1059 \\
62 \\
10481 \\
10475 \\
10474 \mathrm{~B} \\
\text { WG } 1955\end{array}$ & $\begin{array}{l}\text { C } \\
\text { B } \\
\text { C } \\
\text { C } \\
\text { C } \\
\text { B } \\
\text { C } \\
\text { C }\end{array}$ & $\begin{array}{l}1 \mathrm{I}- \\
1 \mathrm{I}- \\
1 \mathrm{I}- \\
1 \mathrm{III}- \\
1 \mathrm{I}- \\
1 \mathrm{III} \\
1 \mathrm{I}- \\
1 \mathrm{III} \mathrm{A}\end{array}$ & \\
\hline C. TIO PIO (N) & 3 & 1205 & & A & $1 \mathrm{III}-$ & $-350 /-300$ \\
\hline CABECICO DEL TESORO & $\begin{array}{l}376 \\
400 \\
448 \\
\end{array}$ & $\begin{array}{l}41 \\
46 \\
54 \\
\end{array}$ & $\begin{array}{l}373 / 2 \\
400 / 6 \\
448 / 1 \\
\end{array}$ & $\begin{array}{l}\mathrm{B} \\
\mathrm{A} \\
\mathrm{B}\end{array}$ & $\begin{array}{l}1 \mathrm{III}- \\
1 \mathrm{III}- \\
1 \mathrm{I}-\end{array}$ & $\begin{array}{r}-400 /-250 \\
-400 /-350 \\
\text { Sin datos } \\
\end{array}$ \\
\hline CIGARRALEJO & $\begin{array}{r}119 \\
124 \\
124 \\
125 \\
128 \\
128 \\
178 \\
205 \\
209 \\
225 \\
23 / 24 \\
277 \\
283 \\
293 \\
30 \\
314 \\
321 \\
350 \\
41 / 42 \\
48 \\
486 \\
98 \\
\end{array}$ & $\begin{array}{l}421 \\
431 \\
432 \\
435 \\
443 \\
444 \\
513 \\
553 \\
558 \\
590 \\
290 \\
622 \\
642 \\
649 \\
300 \\
666 \\
670 \\
699 \\
316 \\
325 \\
842 \\
388 \\
\end{array}$ & $\begin{array}{r}1042 \\
1100 \\
1092 \\
1105 \\
1109 \\
1126 \mathrm{bis} \\
1653 \\
1864 \\
1909 \\
2093 \\
198 \\
2708 \\
2839 \\
2995 \\
255 \\
3426 \\
3437 \\
3655 \\
46 \\
109 \\
5420 \\
871 \\
\end{array}$ & $\begin{array}{l}\text { B } \\
\text { C } \\
\text { B } \\
\text { B } \\
\text { B } \\
\text { B } \\
\text { B } \\
\text { C } \\
\text { B } \\
\text { A } \\
\text { A } \\
\text { A } \\
\text { B } \\
\text { C } \\
A \\
B \\
B \\
B \\
A \\
C \\
B \\
B \\
\end{array}$ & $\begin{array}{l}1 \mathrm{III}- \\
1 \mathrm{I}- \\
1 \mathrm{III}- \\
1 \mathrm{III}- \\
1 \mathrm{III}- \\
1 \mathrm{III}- \\
1 \mathrm{III}- \\
1 \mathrm{III}- \\
1 \mathrm{III}- \\
1 \mathrm{III}- \\
1 \mathrm{II}- \\
1 \mathrm{II}- \\
1 \mathrm{III}- \\
1 \mathrm{III}- \\
1 \mathrm{II}- \\
1 \mathrm{II}- \\
1 \mathrm{III}- \\
1 \mathrm{III}- \\
1 \mathrm{III}- \\
1 \mathrm{III}- \\
1 \\
1 \mathrm{II}-\end{array}$ & 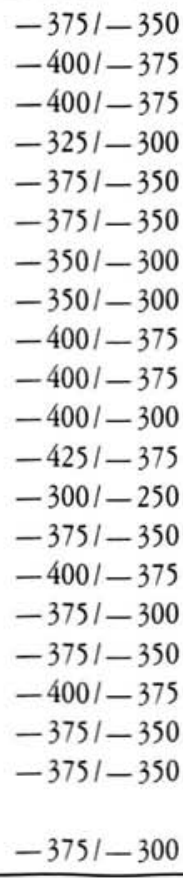 \\
\hline COIMBRA B. ANCHO & 48 & 1129 & NB. 4115 & B & 1 & $-400 /-350$ \\
\hline ILLORA & - & $\begin{array}{l}1401 \\
1402 \\
\end{array}$ & $\begin{array}{l}1306 \\
1308 \\
\end{array}$ & $\begin{array}{l}\text { B } \\
\text { B }\end{array}$ & $\begin{array}{l}1 \mathrm{III} \\
1 \mathrm{II}-\end{array}$ & \\
\hline NOVELDA & - & 1359 & & C & $1 \mathrm{III}-$ & $-400 /-300$ \\
\hline
\end{tabular}


TABLA 2

\begin{tabular}{|c|c|c|c|c|c|c|}
\hline YACIMIENTO & SEP & Fich. & N. INV & TIPO & ACANAL. & DATACION \\
\hline ALMEDINILLA & & $\begin{array}{l}861 \\
864 \\
865 \\
867 \\
872 \\
873 \\
874 \\
875 \\
876 \\
880 \\
883 \\
884 \\
885 \\
886 \\
890 \\
893 \\
899 \\
900 \\
902 \\
903\end{array}$ & $\begin{array}{r}1056 \\
1053 \\
67 \\
1054 \\
64 \\
1062 \\
10477 \\
10471 \\
10469 \\
65 \\
73 \\
56 \\
58 \\
71 \\
10470 \\
10472 \\
10478 \\
104736 i s \\
\text { WG } 2427 \\
\text { WG } 1954\end{array}$ & $\begin{array}{l}\text { C } \\
\text { C } \\
\text { C } \\
\text { C } \\
\text { B } \\
\text { C } \\
\text { A } \\
\text { A } \\
\text { A } \\
\text { C } \\
\text { C } \\
\text { C } \\
\text { C } \\
\text { C } \\
\text { A } \\
\text { C } \\
\text { B } \\
? \\
\text { C } \\
\text { B }\end{array}$ & $\begin{array}{l}2 \mathrm{I}- \\
2 \mathrm{I}- \\
2 \mathrm{II}- \\
2 \mathrm{I}- \\
2 \mathrm{I}- \\
2 \mathrm{I}- \\
2 \mathrm{I}- \\
2 \mathrm{III} \mathrm{CBC} \\
2 \mathrm{II}- \\
2 \mathrm{I}- \\
2 \mathrm{III}- \\
2 \mathrm{III}- \\
2 \mathrm{III}- \\
2 \mathrm{III}- \\
2 \mathrm{II}- \\
2 \mathrm{III}- \\
2 \mathrm{I}- \\
2 \mathrm{III}- \\
2 \mathrm{III} \text { AA } \\
2 \mathrm{III} \mathrm{CACB}\end{array}$ & \\
\hline ALMEDINILLA ? & & $\begin{array}{l}895 \\
896\end{array}$ & $\begin{array}{l}10473 \\
10474 \\
\end{array}$ & $\begin{array}{l}\mathrm{B} \\
\mathrm{C}\end{array}$ & $\begin{array}{l}2 \mathrm{III}- \\
2 \mathrm{III}-\end{array}$ & \\
\hline CIGARRALEJO & $\begin{array}{r}11 \\
111 \\
118 \\
12 \\
123 \\
123 \\
129 \\
129 \\
132 \\
135 \\
138 \\
149 \\
151 \\
153 \\
153 \\
161 \\
17 \\
187 \\
191 \\
212 \\
217\end{array}$ & $\begin{array}{l}275 \\
406 \\
417 \\
279 \\
425 \\
449 \\
450 \\
456 \\
461 \\
468 \\
490 \\
494 \\
498 \\
499 \\
508 \\
285 \\
522 \\
526 \\
564 \\
568\end{array}$ & $\begin{array}{r}149 \\
994 \\
1035 \\
152 \\
1076 \\
1134 \\
1129 \\
1197 \\
1230 \\
1308 \\
1370 \\
1394 \\
1426 \\
1426 \\
1593 \\
171 \\
1737 \\
1478 \\
1945 \\
1996\end{array}$ & $\begin{array}{l}\text { C } \\
\text { A } \\
\text { B } \\
\text { C } \\
\text { A } \\
\text { B } \\
\text { B } \\
\text { B } \\
\text { B } \\
\text { B } \\
\text { B } \\
\text { B } \\
\text { A } \\
\text { A } \\
\text { A } \\
\text { C } \\
\text { A } \\
\text { A } \\
\text { B } \\
\text { A }\end{array}$ & $\begin{array}{l}2 \mathrm{II}- \\
2 \mathrm{II}- \\
2 \mathrm{III}- \\
2 \mathrm{II}- \\
2 \mathrm{III} \mathrm{CC} \\
2 \mathrm{I}- \\
2 \mathrm{II}- \\
2 \mathrm{III}- \\
2 \mathrm{III}- \\
2 \mathrm{III} \mathrm{CB} \\
2 \mathrm{III} \mathrm{DDC} \\
2 \mathrm{III}- \\
2 \mathrm{III}- \\
2 \\
2 \mathrm{III}- \\
2 \mathrm{II}- \\
2 \mathrm{III}- \\
2 \mathrm{III}- \\
2 \mathrm{II}- \\
2 \mathrm{III}-\end{array}$ & $\begin{array}{r}\text { Sin datos } \\
-350 /-325 \\
-375 /-350 \\
-375 /-350 \\
-400 /-350 \\
-325 I-300 \\
-325 I-300 \\
-375 /-325 \\
-325 I-275 \\
-400 /-375 \\
-400 /-350 \\
-400 /-375 \\
-375 /-350 \\
-375 /-350 \\
-400 /-375 \\
-375 I-325 \\
-375 /-350 \\
-400 /-350 \\
-400 /-375 \\
-425 /-375\end{array}$ \\
\hline
\end{tabular}




\begin{tabular}{|c|c|c|c|c|c|c|}
\hline YACIMIENTO & SEP & Fich. & N. INV & TIPO & ACANAL. & DATACION \\
\hline \multirow{22}{*}{$\begin{array}{l}\text { GIGARRALEJO } \\
\text { (continuación) }\end{array}$} & 220 & 580 & 2020 & A & $2 \mathrm{III}-$ & $-375 /-325$ \\
\hline & $223 \mathrm{~B}$ & 586 & 2082 & B & $2 \mathrm{II}-$ & $-400 /-300$ \\
\hline & $223 \mathrm{~B}$ & 587 & 2083 & C & $2 \mathrm{III}-$ & $-400 /-300$ \\
\hline & 236 & 599 & 2166 & A & $2 \mathrm{II}-$ & $-3751-350$ \\
\hline & 243 & 606 & 2292 & A & $2 \mathrm{III}-$ & $-400 /-350$ \\
\hline & 248 & 608 & 2356 & B & $2 \mathrm{III}-$ & $-3751-350$ \\
\hline & 259 & 616 & 2420 & B & $2 \mathrm{II}-$ & $-375 /-300$ \\
\hline & 286 & 647 & 2851 & C & $2 \mathrm{III}-$ & $-400 /-375$ \\
\hline & 301 & 653 & 3035 & B & 2 III B & $-400 /-375$ \\
\hline & 312 & 663 & 3579 & A & $2 \mathrm{I}-$ & $-400 /-375$ \\
\hline & 331 & 674 & 3519 & A & 2 III - & $-400 /-375$ \\
\hline & 332 & 677 & 3524 & B & $2 \mathrm{II}-$ & $-400 /-325$ \\
\hline & 344 & 694 & 2641 & $\mathrm{C}$ & $2 \mathrm{II}-$ & $-400 /-375$ \\
\hline & 382 & 715 & 3989 & C & $2 \mathrm{III}-$ & $-400 /-350$ \\
\hline & 45 & 321 & 73 & B & $2 \mathrm{III}-$ & $-350 /-325$ \\
\hline & 46 & 324 & 100 & B & $2 \mathrm{II}-$ & $-3751-325$ \\
\hline & 59 & 338 & 435 & $\mathrm{C}$ & $2 \mathrm{I}-$ & $-350 /-325$ \\
\hline & 65 & 350 & 497 & B & $2 \mathrm{I}-$ & $-400 /-375$ \\
\hline & 72 & 356 & 527 & B & $2 \mathrm{II}-$ & $-400 /-375$ \\
\hline & 74 & 360 & 665 & A & $2 \mathrm{I}-$ & $-400 /-375$ \\
\hline & 79 & 375 & 703 & A & $2 \mathrm{III}-$ & $-375 /-350$ \\
\hline & 80 & 383 & 716 & C & $2 \mathrm{III}-$ & $-400 /-300$ \\
\hline EL AMAREJO & - & 1283 & - & C & $2 \mathrm{III}-$ & \\
\hline EL CHARPOLAR & - & 1371 & - & C & 2 & \\
\hline \multirow[t]{2}{*}{ El TESORICO } & 7 & 1118 & 561 & A & $2 \mathrm{III}-$ & $-415 /-350$ \\
\hline & 7 & 1119 & 588 & B & $2 \mathrm{III}-$ & $-415 /-350$ \\
\hline HOYA DE S. ANA & 0 & 1078 & 2109 & $\mathrm{C}$ & $2 \mathrm{III}-$ & \\
\hline
\end{tabular}


TABLA 3

\begin{tabular}{|c|c|c|c|c|c|c|}
\hline YACIMIENTO & SEP & Fich. & N. INV & TIPO & ACANAL. & DATACION \\
\hline ALMEDINILLA & & $\begin{array}{l}877 \\
881 \\
887 \\
889 \\
894 \\
862 \\
863 \\
870 \\
\end{array}$ & $\begin{array}{r}1068 \\
1061 \\
1065 \\
10476 \\
\text { s/n. } \\
1066 \\
s / n . \\
1063\end{array}$ & $\begin{array}{l}\text { C } \\
\text { C } \\
\text { C } \\
\text { A } \\
\text { C } \\
\text { C } \\
\text { C } \\
\text { C }\end{array}$ & $\begin{array}{l}0 \mathrm{I}- \\
0 \mathrm{III}- \\
0 \mathrm{I} \\
0 \mathrm{III}- \\
0 \mathrm{I}- \\
0 \mathrm{I}- \\
0 \mathrm{III}- \\
0 \mathrm{I}-\end{array}$ & \\
\hline CABECICO DEL TESORO & $\begin{array}{r}160 \\
220 \\
226 \\
258 \\
260 \\
260 \\
278 \\
318 \\
366 \\
370 \\
38 \\
386 \\
409 \\
428 \\
431 \\
442 \\
452 \\
453 \\
477 \\
98\end{array}$ & $\begin{array}{r}10 \\
19 \\
20 \\
22 \\
24 \\
23 \\
28 \\
32 \\
38 \\
39 \\
5 \\
42 \\
47 \\
50 \\
51 \\
53 \\
56 \\
57 \\
60 \\
7\end{array}$ & $\begin{array}{r}160 / 6 \\
220 / 3 \\
226 / 23 \\
258 / 2 \\
260 / 7 \\
260 / 5 \\
278 / 1 \\
318 / 3 \\
366 / 5 \\
370 / 1 \\
38 / 3 \\
386 / 4 \\
409 / 4 \\
428 / 2 \\
431 / 1 \\
442 / 2 \\
452 / 1 \\
453 / 7 \\
477 / 11 \\
98 / 3\end{array}$ & $\begin{array}{l}\text { B } \\
\text { C } \\
\text { D } \\
\text { B } \\
\text { C } \\
\text { B } \\
\text { C } \\
\text { C } \\
\text { C } \\
\text { A } \\
\text { C } \\
\text { C } \\
\\
\text { B } \\
\text { A } \\
\text { B } \\
\text { C } \\
\text { C } \\
\text { C } \\
\text { C }\end{array}$ & $\begin{array}{l}0 \mathrm{I}- \\
0 \mathrm{I}- \\
0 \mathrm{I}- \\
0 \mathrm{I}- \\
0 \mathrm{I}- \\
0 \mathrm{I}- \\
0 \mathrm{I}- \\
0 \mathrm{I}- \\
0 \mathrm{I}- \\
0 \mathrm{II}- \\
0 \mathrm{I}- \\
0 \mathrm{II}- \\
0 \mathrm{I}- \\
0 \mathrm{I}- \\
0 \mathrm{I}- \\
0 \mathrm{I}- \\
0 \mathrm{I}- \\
0 \mathrm{I}- \\
0 \mathrm{I}- \\
0 \mathrm{I}-\end{array}$ & $\begin{array}{r}-175 /-100 \\
-250 /-200 \\
-250 /-200 \\
\text { Sin datos } \\
-350 /-300 \\
-350 /-300 \\
-190 /-120 \\
-225 /-100 \\
-250 /-50 \\
\text { Sin datos } \\
-400 /-350 \\
-230 /-200 \\
-375 /-340 \\
-300 /-200 \\
\text { Sin datos } \\
\text { Sin datos } \\
\text { Sin datos } \\
-300 /-150 \\
-400 /-280 \\
\text { Sin datos }\end{array}$ \\
\hline CIGARRALEJO & $\begin{array}{l}103 \\
114 \\
115 \\
127 \\
136 \\
159 \\
182 \\
277 \\
308 \\
388 \\
412\end{array}$ & $\begin{array}{l}397 \\
411 \\
413 \\
439 \\
464 \\
503 \\
518 \\
623 \\
659 \\
720 \\
752\end{array}$ & $\begin{array}{r}913 \text { bis } \\
1011 \\
1019 \\
1146 \\
1225 \\
1587 \\
1672 \\
2709 \\
3402 \\
4009 \\
4366\end{array}$ & $\begin{array}{l}\text { B } \\
\text { A } \\
\text { C } \\
\text { A } \\
\text { B } \\
\text { B } \\
\text { C } \\
\text { C } \\
\text { A } \\
\text { B } \\
\text { C }\end{array}$ & $\begin{array}{l}0 \mathrm{III}- \\
0 \mathrm{I} \mathrm{CC} \\
0 \mathrm{I}- \\
0 \mathrm{III}- \\
0 \mathrm{III}- \\
0 \mathrm{III}- \\
0 \mathrm{III}- \\
0 \mathrm{III}- \\
0 \mathrm{I}- \\
0 \mathrm{I}- \\
0 \mathrm{I}-\end{array}$ & $\begin{array}{l}-375 /-350 \\
-425 I-375 \\
-375 /-350 \\
-300 /-275 \\
-400 /-375 \\
-375 /-350 \\
-425 /-375 \\
-400 /-350 \\
-400 /-350\end{array}$ \\
\hline
\end{tabular}




\begin{tabular}{|c|c|c|c|c|c|c|}
\hline YACIMIENTO & SEP & Fich. & N. INV & TIPO & ACANAL & DATACION \\
\hline $\begin{array}{l}\text { CIGARRALEJO } \\
\text { (continuación) }\end{array}$ & $\begin{array}{r}418 \\
420 \\
430 \\
452 A \\
466 \\
55 \\
64 \\
71\end{array}$ & $\begin{array}{l}758 \\
762 \\
774 \\
801 \\
805 \\
332 \\
347 \\
353\end{array}$ & $\begin{array}{r}4389 \\
4397 \\
4456 \\
4890 \\
4988 \\
333 \\
493 \\
515\end{array}$ & $\begin{array}{l}\text { B } \\
\text { B } \\
\text { B } \\
\text { C } \\
\text { B } \\
\text { B } \\
\text { B } \\
\text { B }\end{array}$ & $\begin{array}{l}0 \mathrm{I}- \\
0 \\
0 \\
0 \\
0 \\
0 \mathrm{I}- \\
0 \mathrm{III}- \\
0 \mathrm{III}-\end{array}$ & $\begin{array}{r} \\
-400 /-350 \\
-375 /-325 \\
-400 /-375 \\
-400 /-350\end{array}$ \\
\hline COIMBRA B. ANCHO & $\begin{array}{r}14 \\
16 / 20 \\
30 \\
41 \\
55 \\
8 \\
9 \\
9 \\
\end{array}$ & $\begin{array}{l}1172 \\
1171 \\
1166 \\
1170 \\
1142 \\
1155 \\
1161 \\
1162 \\
\end{array}$ & NB-2626 & $\begin{array}{l}\text { C } \\
\text { C } \\
\text { A } \\
\text { C } \\
\text { B } \\
\text { C } \\
\text { C } \\
\text { C }\end{array}$ & $\begin{array}{l}0 \\
0 \\
0 \\
0 \\
0 \\
0 \\
0 \\
0\end{array}$ & \\
\hline HOYA DE S. ANA & 27 & 1094 & 2253 & C & $0 \mathrm{I}-$ & \\
\hline LA ALBUFERETA & $\begin{array}{l}\text { F } 101 \\
\text { F } 113 \\
\text { F } 132 \\
\text { F } 138 \\
\text { L } 41\end{array}$ & $\begin{array}{l}1295 \\
1298 \\
1300 \\
1303 \\
1315 \\
\end{array}$ & $\begin{array}{r}5366-67 \\
\text { NA } 5338 \\
\text { NA } 5369 \\
\text { NA } 5339 \\
\text { NA } 5336 \\
\end{array}$ & $\begin{array}{c}\text { C } \\
\text { C } \\
\text { A? } \\
\text { B }\end{array}$ & $\begin{array}{l}0 \\
0 \text { III }- \\
0 \\
0 \text { III }- \\
0 \text { III }-\end{array}$ & $\begin{array}{r}\text { Sin datos } \\
\text { Sin datos } \\
\text { Sin datos } \\
\text { Sin datos } \\
\text { s. IV? }\end{array}$ \\
\hline LA SENDA & $\begin{array}{l}8 \\
9 \\
\end{array}$ & $\begin{array}{l}1196 \\
1198 \\
\end{array}$ & $\begin{array}{l}2376 \\
2382 \\
\end{array}$ & $\begin{array}{l}\mathrm{C} \\
\mathrm{C}\end{array}$ & $\begin{array}{l}0 \\
0 \\
\end{array}$ & $\begin{array}{r}-400 /-350 \\
\text { Sin datos }\end{array}$ \\
\hline LOS NIETOS & $\begin{array}{r}27 \\
8\end{array}$ & $\begin{array}{l}1065 \\
1056\end{array}$ & $\begin{array}{l}\text { T27.7 } \\
\text { T8-13 }\end{array}$ & $\begin{array}{l}\mathrm{C} \\
\mathrm{C}\end{array}$ & $\begin{array}{l}0 \mathrm{I}- \\
0 \mathrm{I}-\end{array}$ & $\begin{array}{l}-375 /-350 \\
-425 /-350\end{array}$ \\
\hline
\end{tabular}




\section{Bibliografia}

BURTON, R. F. (1884): "The book of the Sword", London. (Reed. facsimil, 1987).

CABRE, M. E. (1934): "Dos tipos genéricos de falcata hispánica”, Archivo Español de Arte y Arqueología 30, 2-18.

Coghlan, H. H. (1956-57): «Etruscan and Spanish swords of Iron", Sibrium 3, 167-171.

Cuadrado Díaz, E. (1987): «La necrópolis ibérica de "El Cigarralejo" (Mula, Murcia)», Bibliotheca Praebistorica Hispana XXIII, Madrid.

CUADRADO DíAZ, E. (1989): La panoplia de los iberos de "El Cigarralejo».

García-Gelabert Pérez, M. P. y BlázQuez MARTíneZ, J. M. (1989): «El armamento de las necrópolis ibéricas de la alta Andalucían, Historia 16, 153, 105-112.

LATORRE NUÉVALOS, F. (1979): "Aproximación al estudio del armamento ibérico levantino", Varia $I$. Serie Arqueológica, 6, 153-182.

LEÓN ALONSO, M. P. (1981): "Plástica ibérica e iberorromana", La Baja Epoca de la Cultura Ibérica, 183-199.

Nieto Gallo, G. y Escalera Ureña, A. (1970): «Estudio y tratamiento de una falcata de Almedinilla». Informes y Trabajos del Instituto de Conservación y Restauración de obras de Arte, Arqueologia y Etnologia $10,5-30$.

Quesada SANZ, F. (1989): “Armamento, Guerra y Sociedad en la Necrópolis ibérica de "El Cabecico del Tesoro" (Murcia, España)», B. A. R. International Series, 502, 2 vols. Oxford.

QUESADA SANZ, F. (e. p.): "En torno al origen y procedencia de la Falcata ibérica", Archivo Español de Arqueología.

RUANO RUIZ, E. (1987): La Escultura bumana de piedra en el mundo ibérico, Madrid, 3 vols.

TYLECOTE, R. F. (1987): The early History of Metallurgy in Europe, London. 